\title{
Additive Effect of Sulfantil to Lidocain and Bupivacain for Supraclavicular Brachial Plexus Block
}

\author{
D. S. Lodhe, V. V. Akulwar, and S. Deshmukh
}

\section{ABSTRACT}

Purpose: We evaluated the effect of adding Sufentanil to the mixture of Lidocaine and Bupivacaine used for supraclavicular brachial plexus block in reducing postoperative pain.

Method: This double-blind clinical intervention trial was conducted in 2007. Patients scheduled to undergo upper limb orthopedic surgeries under supraclavicular brachial plexus block were recruited. Participants of one arm were given the mixture of Sufentanil, lidocaine, and bupivacaine (Group S) while those of the other arm were given the mixture of later two drugs (Group C). Postoperative pain assessment was done every hour postoperatively till the first administration of systemic analgesic. We used a subjective pain score and duration of lack of muscle movement as a parameter to judge outcomes. The mean and standard deviation were compared of both arms.

Result: We included 50 patients in both arms. The mean duration of the motor blockade in group $S$ and $C$ were $342.8( \pm 145.4)$ and $171.1( \pm 50.2)$ minutes respectively. The additive effect of Sufentanil in motor blockage was $171.7(95 \%$ CI $128.5-214.9)\left(p=0.1 \times 10^{-6}\right)$. The mean duration of analgesia in group $S$ and $C$ were $892( \pm 34.7)$ and $350( \pm 72.1)$ minutes respectively. The additive effect of Sufentanil in analgesia was $542(95 \%$ CI 524-559) $\left(p=0.1 \times 10^{-6}\right)$. In group $S$, one patient developed cardiac pain following pneumothorax and two had temporary Horner syndrome.

Conclusion: Analgesia in the postoperative period can be enhanced with the addition of Sufentanil (an opioid) to local anesthetics in supraclavicular brachial plexus block.

Keywords: Brachial plexus block, Bupivacain, Supraclavicular, Lidocain.
Submitted : January 21, 2021

Published : May 12, 2021

ISSN: 2593-8339

DOI: $10.24018 /$ ejmed.2021.3.3.688

\section{S. Lodhe*}

Dept. of anesthesia, King Khaled Specialist Eye Hospital, Riyadh, Saudi Arabia.

(e-mail: dlodhe@ rediffmail.com)

V. V. Akulwar

Lata Mangeshkar Hospital, Nagpur,

Maharashtra, India.

S. Deshmukh

Lata Mangeshkar Hospital, Nagpur, Maharashtra, India.

*Corresponding Author

\section{INTRODUCTION}

Pain is an unpleasant, sensory, and emotional experience associated with actual or potential tissue damage. Peripheral nerve blockade is now a well-accepted component of comprehensive anesthetic care. Brachial plexus block is an established regional anesthetic technique for upper limb surgeries.

The use of systemic opioids is still the most common method of achieving postoperative analgesia.

If both these approaches are combined patient will have better anesthesia. This was attempted by other researchers [1]-[3]. However, few have attempted a mixture of opioids and conventional anesthetic agents in the supraclavicular approach of brachial plexus block. [4]. Sufentanil among all opioids is highly lipid-soluble and therefore has better penetration of the myelin [5].

We evaluated the additive effect of sufentanil to the local anesthetic mixture of lidocaine and bupivacaine about the duration of analgesia and the quality of postoperative pain relief when given in supraclavicular brachial plexus block.

\section{METHODS}

The institutional ethics committee approved of this study. Written informed consent of the participants was obtained.

Adult patients having ASA physical class I and II [5], aged 20 to 70 years and weighing $50-90 \mathrm{~kg}$ was included. They were scheduled to undergo upper limb orthopedic surgeries either elective or emergency under supraclavicular brachial plexus block.

To calculate sample size in our study we assumed that the mean difference in two arms was 10 hours [6]. To achieve a $5 \%$ confidence interval, $80 \%$ power of study with 1 to 1 ratio of the sample in both arms we needed 45 cases in each group. To compensate for the loss of participants we increased the sample by $10 \%$. Thus, we included 50 patients in group s and group $\mathrm{C}$ in our study.

We excluded uncooperative patients and those with any systemic disease, lidocaine sensitivity, local infection, having contralateral phrenic nerve palsy and contralateral pneumothorax, bleeding disorders, and patients less than $50 \mathrm{~kg}$ and more than $90 \mathrm{~kg}$. 
Thorough general and systemic examination was done. Patients were explained about the procedure and the advantages of postoperative pain relief. Informed consent was obtained, and local anesthetic sensitivity testing was done. Patients were divided randomly into two groups. Patients of Group C received Inj. Bupivacaine $0.5 \%$ $1.5 \mathrm{mg} / \mathrm{kg}+\mathrm{Inj}$. Lidocaine $1.0 \% 3.0 \mathrm{mg} / \mathrm{kg}$. Patients of Group $\mathrm{S}$ received Inj. Bupivacaine $0.5 \% 1.5 \mathrm{mg} / \mathrm{kg}+\mathrm{Inj}$. Lidocaine $1.0 \% 3.0 \mathrm{mg} / \mathrm{kg}$ and Inj. Sufentanil $0.2 \mathrm{mg} / \mathrm{kg}$.

Brachial plexus block was performed with a 22 gauge, $4 \mathrm{~cm}$ needle through the supraclavicular approach.

Duration of motor block was defined as the time between motor block and ability to do all movements. Duration of sensory block was defined as the time between block and time of patient perceiving the pinprick sensation. Duration of analgesia was the time between the administration of drugs and the first injection of systemic analgesic.

Postoperative pain was assessed every hour from zero hours postoperatively to the first administration of systemic analgesic. We used a subjective pain scoring method with grades from 0 to 100 . The patients were asked to quantify their pain subjectively in the form of a fraction of a rupee (e.g., 25 paise, 50 paise out of a rupee). The quality of anesthesia was graded as good fair and poor if scores were ' 0 to 30 ', ' 31 to 60 ', ' 61 to 100 ' respectively.

Side effects and complications of systemic opioid absorption and supraclavicular technique, such as nausea, vomiting, drowsiness, pruritus, urinary retention, respiratory depression, pneumothorax, hematoma, Horner's syndrome, phrenic nerve palsy was observed and treated accordingly.

The patient was not aware of which arm they belong to. The person who was measuring the outcomes was also blinded about the status of the patient about the study group.

We entered data in the Microsoft XL spreadsheet. To compare the outcomes of the two arms we calculated mean and standard deviation and then the difference of mean with its $5 \%$ confidence interval

\section{RESULTS}

We had 50 cases in group S and 50 cases in Group C. The mean age of patients in group $S$ was $35.9 \pm 14.1$ years whereas its $\mathrm{C}$ was $36.9 \pm 14.4$ years, in group $\mathrm{C}$. The age difference was not significant $(\mathrm{p}=0.88)$. The mean weight of patients of group $\mathrm{S}$ was $56.0 \pm 4.5 \mathrm{~kg}$ and it was $55.0 \pm 5.0 \mathrm{~kg}$ in patients of group $\mathrm{C}$. The age difference was not significant $(\mathrm{p}=0.46)$. The mean duration of surgery in Group $\mathrm{S}$ was 100.5 \pm 52.0 . While the mean duration of surgery in Group $\mathrm{C}$ patients was $91.9 \pm 50.8$ minutes. The difference in duration of surgery in the two groups was not significant $(\mathrm{p}=0.87)$

The mean duration of the motor blockade in group $\mathrm{S}$ and $\mathrm{C}$ were $342.8( \pm 145.4)$ and $171.1( \pm 50.2)$ minutes respectively. The additive effect of Sufentanil in motor blockage was 171.7 (95\% CI 128.5-214.9) minutes $\left(\mathrm{p}=1 \times 10^{-6}\right)$. The mean pain score was reviewed at different postoperative periods. It is displayed in Fig. 1.

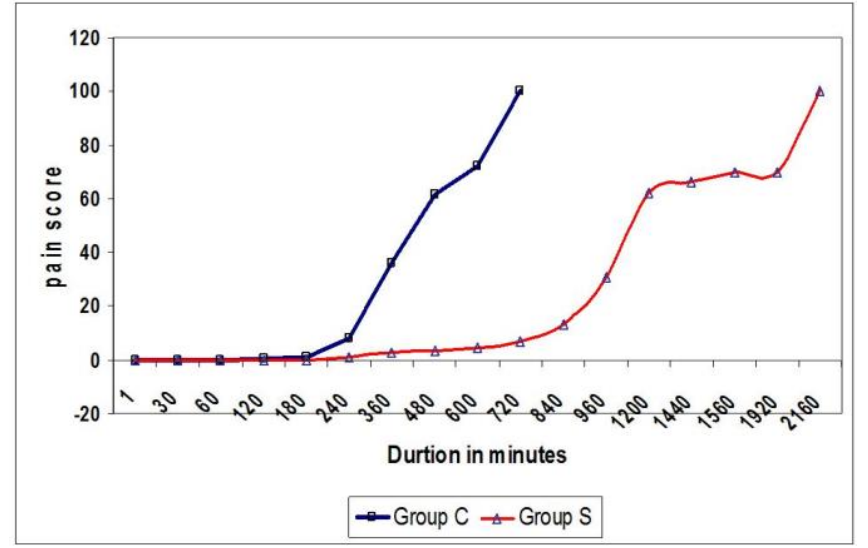

Fig. 1. Duration of analgesia in minutes in group $\mathrm{C}$ and group $\mathrm{S}$.

The mean duration of analgesia in group $\mathrm{S}$ and $\mathrm{C}$ were 892 $( \pm 34.7)$ and $350( \pm 72.1)$ minutes respectively. The additive effect of Sufentanil in analgesia was 542 (95\% CI 524-559) minutes. $\left(p=0.1 \times 10^{-6}\right)$.

In group $\mathrm{S}$, one patient developed cardiac pain following pneumothorax and two had temporary Horner syndrome.

\section{DISCUSSION}

Sufentanil is beneficial when added to a local anesthetic mixture for supraclavicular brachial plexus block. It had better quality and a longer duration of postoperative analgesia. This addition can be useful in ASA grade III and IÑ patients with associated medical problems where general anesthesia may have a greater risk.

The additive effect of Sufentanil in increasing duration of muscle block that was noted in our study matched with the findings of Gormley WP [7]. They used axillary brachial plexus block and also reported that absorption of opioids by injecting near axillary nerve sheath was better than parental administration. Sadeshi SA in Iran used pethidine in addition to lidocaine and fentanyl and found a similar additive effect in muscle block [3]. Kepral in their study in Ausria had added tramadol to local anesthetics in the axillary block and found it useful [8]. Peripheral perineural administration of opioids has been shown to have beneficial effects. Gissen AJ suggested that fentanyl and sufentanil may suppress conduction in peripheral nerves when administered into the nerve sheath. An effect similar to the action of local anesthetic i.e., blocking of conduction had been proposed apart from the peripheral opioid receptors [9].

Prolonging the anesthetic effect by adding Sufentanil was very beneficial to our participants postoperatively. Bezin noted 24 hours prolongation of anesthesia in the supraclavicular block in which Sufentanil was added [10]. This was noted by many other researchers. Although different types of blocks and different opioids were used to reach same conclusions [11], [12]-[15]. In contrast, Bouaziz et al. found no significant benefit of opioids in enhancing the analgesic effect of local anesthetics [16].

No technique is free from any complications. The same is true for the supraclavicular approach of brachial plexus block. Opioids have side effects like nausea, vomiting, drowsiness, pruritus, respiratory depression, and urinary retention [17]. 
Bezin et al. had reported a higher rate of side effects [4]. In contrast, Kepral et al. did not have any side effects [8].

There were few limitations in our study. We used the subjective score to assess pain response in our patients. This was different from the pain analog used by other researchers. Given limited understanding among our rural participants, the use of an international 10 point score for pain measurement was not possible [18].

\section{Conclusions}

Analgesia in postoperative period can be enhanced with the addition of Sufentanil (an opioid) to local anesthetics in supraclavicular brachial plexus block.

\section{REFERENCES}

[1] Sadeghi SA, Soleimani AA, Soleimani M. Supplemental Pethidine and Fentanyl to local anesthetics in supraclavicular block. Acta Medica Iranica. 2003;41(2):134-37.

[2] Lilker S, Rofaeel A, Balki M, Carvalho JC. Comparison of fentanyl and sufentanil as adjuncts to bupivacaine for labor epidural analgesia. J Clin Anesth. 2009;21(2):108-12.

[3] Bullingham RE, McQuay HJ, Moore RA. Studies on the peripheral action of opioids in postoperative pain in man. Acta Anaesthesiol Belg. 1984;35Suppl:285-90.

[4] Bazin JE, Massoni C, Bruelle P, Fenies V, Groslier D, Schoeffler P. The addition of opioids to local anaesthetics in brachial plexus block: the comparative effects of morphine, buprenorphine and sufentanil. Anaesthesia. 1997;52(9):858-62.

[5] ASA Physical Status Classification System http://www.dhed.net/ASA\%20Physical\%20Status\%20Classification\% 20SYSTEM.htm last accessed on 18/12/2012.

[6] Candido KD, Winnie AP, Ghaleb AH, Fattouh MW, Franco CD. Buprenorphine added to the local anesthetic for axillary brachial plexus block prolongs postoperative analgesia. Reg Anesth Pain Med. 2002;27(2):162-7.

[7] Gormley WP, Murray JM, Fee JP, Bower S. Effect of the addition of alfentanil to lignocaine during axillary brachial plexus anaesthesia. $\mathrm{Br}$ J Anaesth. 1996;76(6):802-5.

[8] Kapral S, Gollmann G, Waltl B, et al. Tramadol added to mepivacaine prolongs the duration of an axillary brachial plexus blockade. Anesth Analg. 1999;88(4):853-6.

[9] Gissen AJ, Gugino LD, Datta S, Miller J, Covino BG. Effects of fentanyl and sufentanil on peripheral mammalian nerves. Anesth Analg. 1987;66(12):1272-6.

[10] Bazin JE, Massoni C, Bruelle P, Fenies V, Groslier D, Schoeffler P. The addition of opioids to local anaesthetics in brachial plexus block: the comparative effects of morphine, buprenorphine and sufentanil. Anaesthesia. 1997;52(9):858-62.

[11] Robaux S, Blunt C, Viel E, Cuvillon P, Nouguier P, Dautel G, Boileau $\mathrm{S}$, Girard F, Bouaziz H. Tramadol added to $1.5 \%$ mepivacaine for axillary brachial plexus block improves postoperative analgesia dosedependently. Anesth Analg. 2004;98(4):1172-7.

[12] Nishikawa K, Kanaya N, Nakayama M, Igarashi M, Tsunoda K, Namiki A. Fentanyl improves analgesia but prolongs the onset of axillary brachial plexus block by peripheral mechanism. Anesth Analg. 2000;91(2):384-7.

[13] Antonucci S. Adiuvants in the axillary brachial plexus blockade. Comparison between clonidine, sufentanil and tramadol. Minerva Anestesiol. 2001;67(1-2):23-7.

[14] Viel EJ, Cuvillon P, Eledjam JJ. Opioid and local anesthetic combination for brachial plexus block to provide postoperative analgesia. Reg Anesth Pain Med.2002;27(3):336.

[15] Mannion S, O'Callaghan S, Murphy DB, Shorten GD. Tramadol as adjunct to psoas compartment block with levobupivacaine $0.5 \%$ : a randomized double-blinded study. Br J Anaesth. 2005;94(3):352-6.

[16] Bouaziz H, Kinirons BP, Macalou D, et al. Sufentanil does not prolong the duration of analgesia in a mepivacaine brachial plexus block: a dose response study. Anesth Analg. 2000;90(2):383-7.

[17] Wajima Z, Shitara T, Nakajima Y, et al. Comparison of continuous brachial plexus infusion of butorphanol, mepivacaine and mepivacaine-butorphanol mixtures for postoperative analgesia. $\mathrm{Br} \mathrm{J}$ Anaesth. 1995;75(5):548-51.
[18] Gkotsi A, Petsas D, Sakalis V, Fotas A, Triantafyllidis A, Vouros I Saridakis E, Salpiggidis G, Papathanasiou A. Pain point system scale (PPSS): a method for postoperative pain estimation in retrospective studies. J Pain Res.2012;5:503-10. 